\title{
Museus virtuais de ciências: uma revisão e indicações técnicas para o projeto de exposições virtuais.
}

\author{
Marcelo Leandro Eichler • \\ José Claudio Del Pino *
}

Resumo: $\mathrm{O}$ desenvolvimento de museus e exposições virtuais de ciências contribui para a qualificação do ensino das ciências, com ênfase na criatividade, experimentação, argumentação e interdisciplinariedade. Neste artigo de revisão, pretendemos indicar alguns argumentos encontrados na literatura sobre a popularização das ciências e a inclusão digital, a didática das ciências e sua relação com a visitação de museus de ciências e as tecnologias utilizadas no desenvolvimento de exposições virtuais. Por fim, sugerimos algumas alternativas técnicas que podem ser utilizadas na implementação de museus virtuais de ciências, exemplificando-as em relação à mineralogia.

Palavras-chave: museu de ciências; educação em ciências; interatividade.

Abstract: [Virtual Science Museums: a review and technical suggestions for virtual exhibition projects]. The development of virtual science museums and exhibitions contributes to the qualification of science education, emphasizing creativity, experimentation, and argumentation skills and also the interdisciplinarity. In this paper, we present some arguments found in the literature about science popularization and digital inclusion, as well as sciences education and its relationship with science museum visiting, and the technologies employed in virtual exhibitions. Finally, we suggest some technical alternatives that could be employed on the implementation of virtual science museums.

Keywords: science museum; science education, interactivity.

Inclusão social e popularização da ciências.

Os discursos das políticas públicas visando a educação e o desenvolvimento da ciência e da tecnologia evidenciam a relação entre a inclusão social e a popularização das ciências. Conforme Moreira (2006), "um dos aspectos da inclusão social é possibilitar que cada brasileiro tenha a oportunidade de adquirir conhecimento básico sobre ciência e seu funcionamento que lhe dê condições de entender o seu entorno, de ampliar suas oportunidades no mercado de trabalho e de atuar politicamente com conhecimento de causa" (p. 11). Assim, "consideradas as características do mundo moderno, a educação informal, aí incluída a divulgação científica (termo utilizado aqui também no sentido da popularização da C\&T) tem adquirido importância crescente" (p. 11).

No âmbito da RedPop (Rede de Popularização da Ciência e Tecnologia na América Latina e no Caribe), programa da UNESCO (Conselho das Nações Unidas para a Educação,

\footnotetext{
- Licenciado em Química e Doutor em Psicologia do Desenvolvimento pela UFRGS, é professor da UERGS e pesquisador da Área de Educação Química (AEQ) da UFRGS. Autor correspondente: exlerbr@yahoo.com.br.

* Licenciado em Química PUC-RS, Especialista em Ensino de Química UCS, Doutor em Química de Biomassa UFGRS, é professor do Instituto de Química e coordenador da AEQ-UFRGS.
} 
a Ciência e a Cultura), por exemplo, estão contemplados quatro eixos na popularização da ciência e da tecnologia (C\&T): os centros ou museus interativos de ciência e tecnologia; os programas multimídia; os meios de comunicação de massa (televisão, rádio, imprensa escrita e Internet) e a educação formal, a aprendizagem das ciências (Martínez, 1997).

Segundo Moreira (2006), nas últimas duas décadas tem sido observada uma expansão significativa de ações relacionadas à divulgação científica no Brasil (entre outras, criação de museus e centros de ciências, surgimento de revistas e sítios da internet especializados, publicação de livros e organização de eventos), mas o quadro geral pode ser considerado frágil e limitado com amplas parcelas da população brasileira sem acesso à educação científica e à informação qualificada sobre ciência e tecnologia. Por exemplo, os museus de ciência estão fortemente concentrados em poucas áreas do país. Assim, apesar do crescimento nos últimos anos, "um número muito pequeno de brasileiros, cerca de $1 \%$ da população, visita algum centro ou museu de ciências a cada ano" (para fins comparativos, a visitação a museus em alguns países europeus chega a atingir $25 \%$ da população). Além do que, como indica esse mesmo autor, faltam estudos e análises mais aprofundadas sobre as estratégias, prática e o impacto de atividades de divulgação e sobre as características, atitudes e expectativas da audiência.

A didática das ciências e os museus de ciências.

Conforme Van Praët (2004), a concepção contemporânea de museu compreende: a) uma instituição para a preservação das produções da natureza e da genialidade humana (utilizando as expressões iniciais sobre museus, durante o Século XVIII); e b) um espaço para a comunicação cultural aberta para um amplo público, incidindo sobre os registros do conhecimento e divertimento (tomando as expressões corrente do International Council of Museums - ICOM - UNESCO - www.icom.org).

Segundo esse autor, desde o fim do Século XIX, a emergência de novas representações e disciplinas mudou significativamente os conceitos e o papel dos museus, particularmente dos museus de ciências. Para a comunidade científica estadunidense e européia, as iniciativas de disseminação e popularização foram consideradas indispensáveis, no sentido de propagar os novos conceitos de evolução e ecologia, por exemplo. O dilema entre manter o potencial de pesquisa das coleções e organizar as exibições foi resolvido pela criação do conceito moderno de museus, que separa os espaços do museu em depósitos, doravante de domínio dos especialistas, e salas de exibição, onde esses mesmos especialistas distribuem discursos adaptados à sociedade, ocasionalmente criando novas formas de exibição, como panoramas e diaporamas, envolvendo, principalmente, temas ambientais.

De acordo com Hein (1995), o modelo tradicional de museu, chamado de sistemático, é baseado no ponto de vista que: i) o conteúdo do museu deve ser exibido de forma a refletir a "verdadeira" estrutura da disciplina ou do tema exibido; e ii) o conteúdo deve ser apresentado ao visitante de maneira que seja mais facilmente compreendido. Segundo esse autor, os museus organizados sob princípios sistemáticos são comuns e ele cita o Deutches Museum, em Munique, Alemanha (www.deutsches-museum.de), que pretende ilustrar a estrutura das ciências, e o Harvard Museum of Comparative Zooology (www.mcz.harvard.edu), que foi projetado por Louis Agassiz com a intenção de refutar Charles Darwin, ilustrando a "verdadeira" classificação dos animais.

Um outro modelo de museu se apropria das teses pedagógicas e didáticas divulgadas sob o rótulo de construtivismo. Exemplos de museus construtivistas são difíceis 
de encontrar, porém exibições que permitam os visitantes tirar suas próprias conclusões sobre os significados da mostra são baseados nos princípios construtivistas. Existe, também, um crescente número de exibições que são projetadas de forma que múltiplos caminhos sejam possíveis através da mostra e o visitante (estudante) é suprido com várias modalidades para adquirir informação. Assim, conforme Hein (1995), o construtivismo é particularmente apropriado como base para a educação em espaços não-formais, ainda mais quando se considera a ampla faixa etária dos visitantes de museus.

Segundo Van Praët (2004), o desenvolvimento da interatividade em exibições de centros de ciências, como o Exploratorium (www.exploratorium.edu), em São Francisco (EUA), criados ao final dos anos 1960, tornaram-se um modelo que influenciou quase a totalidade dos museus de ciência e tecnologia, revolucionando a prática da museologia científica.

Conforme Melber e Abraham (2002), entre as décadas de 1960 e 1970, a educação, uma vez mais, passou a ser o principal objetivo dos museus de ciências. A reafirmação dos museus como uma instituição pública surge, nessa época, em oposição à percepção pública dessas instituições como elitistas, irrelevantes e excludentes. Em uma época de grandes mudanças sociais, o espaço informal dos museus refletiu a experimentação e os métodos da educação formal. Nesse período, as teorias educacionais fundamentadas em técnicas de ensino envolvendo manipulação (hands-on) e na aprendizagem baseada em apoio concreto foram amplamente divulgadas. O conceito de salas de descoberta foi introduzido e adotado por numerosas instituições e museus. A ênfase pedagógica subjacente a esses ambientes é propiciar ao visitante a descoberta ou invenção do significado dos objetos em exposição através de sua própria interação, ao invés da instrução didática formal.

Semper (1997) e Bevan (2007) descrevem e analisam a experiência do Exploratorium em relação à educação em ciências em espaços informais. Bevan (2007) indica que existe uma compatibilidade entre os museus interativos, o movimento de reforma curricular dos anos 1960 e os postulados da Escola Nova. Segundo essa autora, o movimento em prol dos museus interativos de ciências começou a partir da revitalização das práticas educativas e científicas baseadas na pergunta. Os projetos de reforma curricular dos anos 1960, como o Nuffield, na Inglaterra, enfatizaram o desenvolvimento da compreensão das disciplinas através do engajamento em atividades científicas, incluindo a utilização de ferramentas, de práticas e de sistemas simbólicos científicos. Nessa abordagem, é essencial auxiliar as crianças a propor questões, explorar e investigar idéias, testar hipóteses e comunicar seus resultados. Dessa forma, os museus interativos de ciências passaram a projetar experiências de aprendizagem que fossem menos orientadas a objetos (como nos tradicionais museus de ciências, onde os objetos são exibidos em caixas de vidro) e mais dirigidas pelo processo (sendo esse conectado ao objeto ou fenômeno real sob investigação). Assim, os museus de ciências deixaram de ser "bibliotecas de conhecimento", tornando-se "bibliotecas de experiências", gerando espaços inovadores, comprometidos com a transformação do ensino e da aprendizagem das ciências.

Por sua vez, Semper (1997) descreve algumas pautas que são utilizadas para chegar a um bom projeto de uma exposição educativa no Exploratorium: a) o usuário de uma exposição, não o seu projetista, deve controlar a atividade de aprendizagem; b) os objetos e as experiência cotidianas permitem bons pontos de partida para muitas exposições; c) é decisivo desenvolver a estética da exposição; d) os artistas, assim como os cientistas e os educadores, podem ser fontes de idéias para interessantes exposições; e) o projeto funcional 
de uma exposição é importante para a aprendizagem; f) as exposições possuem uma escala individual e uma identidade de grupo; e g) o entorno total do museu é importante.

É por tudo isso que Rennie e Williams (2006) sugerem que os museus de ciências podem oferecer oportunidades aos visitantes de adquirir uma compreensão da ciência como um processo de construção de explicações sobre fenômenos naturais na maneira como eles são contextualizados pela cultura prevalecente.

Avaliações sobre a visitação aos museus.

A preocupação e as pesquisas sobre a relação entre a educação formal e os espaços dedicados a educação informal tem sido abordada em periódicos dedicados à educação em ciências. Cox-Petersen, Marsh, Kisiel e Melber (2003) investigaram visitas guiadas de estudantes do ensino fundamental a museus de ciências e de história natural e evidenciaram que os estudantes indicaram grande satisfação com a excursão, porém obtiveram baixos índices de aprendizagem em ciências.

$\mathrm{Na}$ pesquisa realizada por Rennie e Williams (2006) foi evidenciado que, do ponto de vista dos visitantes, um museu tradicional de ciências naturais, assim como uma enciclopédia, é interpretado de forma positiva como um recurso educacional geral. Nesse sentido, o museu foi percebido como um lugar que pode auxiliar os visitantes a entender mais sobre ciência, mesmo que a maioria dos visitantes reconheça pouca mudança em suas idéias sobre as ciências. Desde a perspectiva dos funcionários, o museu prima por seu papel como uma entidade científica, mas sua função educacional é somente parcialmente realizada. Os autores indicaram que os funcionários manifestam a dificuldade de se estabelecer uma efetiva comunicação com os visitantes em relação a natureza e aos processos da ciência.

As observações de Tal e Morag (2007) indicam que os principais padrões de visitação a museus, entre estudantes da escola básica, são direcionadas por guias ou professores e orientadas por tarefas e atividades didáticas. Entretanto, a menor parte dos professores que participaram da pesquisa se envolveram em atividades ou no auxílio aos guias no sentido de esclarecer ou ajudar os estudantes a compreender as explicações científicas subjacentes às exposições visitadas. Nesse sentido, esses autores sugerem que os museus deveriam alterar os modelos de suas exibições, de uma forma tradicional, baseada na transmissão/recepção do conhecimento para um modelo contextualizado sócioculturalmente.

Bamberger e Tal (2007), em outra investigação sobre a aprendizagem em museus, indicam que a aprendizagem promovida "ao ar livre" (informal) é diferente daquela que se realiza em sala de aula (formal) e, nesse sentido, a aprendizagem despreocupada e natural em museus acentua a manifestação da aprendizagem em contextos pessoais. Assim, com toda a oportunidade de escolhas, os estudantes associam sua visita as suas próprias experiências de vida e aos seus conhecimentos prévios, mesmo quando as atividades guiadas raramente apontam a isso.

Kelly (2004) compreende que através do acesso aos objetos, conhecimentos e informações exibidas nos museus, os visitantes observam a sua cultura e a si mesmos refletidos de uma maneira que os encoraja a fazer novas conexões, aprender e elaborar significados. Dessa forma, os museus têm a oportunidade de moldar identidades.

Porém, é preciso ressaltar a advertência feita por Adams (2007) que, ao concordar que a identidade é um fator de motivação para a visitação de museus, também, sugeriu que os afro-descendentes podem se sentir oprimidos na maneira eurocêntrica como os povos 
africanos são descritos e interpretados em museus, como o American Museum of Natural History (www.amnh.org), que a autora analisa. Nesse sentido, Melber e Abraham (2002) indicam que esse museu foi construído sob a tradição dos museus europeus de história natural do Século XIX, onde as coleções privadas de objetos da natureza, coletados e identificados pelos membros da classe dominante, eram expostos de forma "filantrópica", mesmo que as coleções fossem sujeitas às proteções de propriedades e de uso (royalties) e fossem acessíveis somente para indivíduos privilegiados por classe.

Análises mais amplas, de interesse à história da ciência, podem ser encontradas em Alberti (2005) e Forgan (2005). Por exemplo, Alberti (2005) mostra que a distinção entre os museus e os espaços comerciais nem sempre foram visíveis, pois muitos comerciantes apresentavam um conjunto de objetos representativos do "conhecimento natural", que poderiam ser adquiridos prontamente pelos visitantes, ao lado das exibições das coleções de "interesse científico". Desde outro ponto de vista, Forgan (2005) indica que a própria construção de museus esteve envolvida por disputas sobre concepções de conhecimento e objetivos institucionais, oferecendo um espaço de prestígio às comissões que deliberavam sobre as opções em disputa e reconhecimento aos arquitetos que tiveram seus projetos escolhidos.

Por isso, Adams (2007) sustenta que a visitação aos museus tradicionais pode ser um momento para trazer à discussão a ideologia subjacente às mostras e exibições dos museus e a proposição de diferentes interpretações e explicações dos dados e fenômenos científicos apresentados nesse espaço institucional. Em relação aos possíveis projetos de museus virtuais, suas análises e críticas são importantes advertências a serem levadas em conta na etapa de modelagem das exibições virtuais que podem ser realizadas.

Além disso, sobre a relação entre museus e a educação em ciências, Adams (2007) sugere que é necessário criar estruturas que possibilitem aos estudantes acessarem e se apropriarem dos conhecimentos científicos de um modo que encoraje o processo de hibridização e permita aos estudantes perceber a ciência como uma parte de suas experiências cotidianas. Nesse sentido, mostra como os professores de ciências podem utilizar as visitas aos museus, zoológicos e jardins botânicos para solicitar aos estudantes que realizem, em contexto escolar, suas próprias mostras, de acordo com seus interesses. No artigo, a autora relata uma experiência de uma professora de escola pública que desempenhou um papel de "curadora científica" nas exibições elaboradas pelos alunos do último ano do ensino fundamental, que envolveram temas como: mudanças climáticas e aquecimento global, reprodução de mosquitos e crescimento de cristais.

Os museus e as exposições virtuais.

Os museus de ciências podem ser transpostos para o formato digital através de diversas tecnologias. Núñez e Ochoa (2006) descrevem um objeto de aprendizagem em que os alunos podem fazer um passeio virtual pelas dependências de um museu e acessar as informações e os artefatos dispostas em vitrines, bem como acessar a navegação de hipertextos que descrevem as exibições. No objeto de aprendizagem, pode-se observar em detalhe os artefato expostos e investigar mais informações sobre ele junto ao hipertexto. A todo momento da visita, apresenta-se uma planta baixa que permite situar o visitante em que parte do museu ele se encontra. Além disso, propõe-se uma atividade prática de comparação e de classificação com a intenção de possibilitar que os alunos estabeleçam seus próprios critérios de descrição e de classificação para os artefatos expostos. 
Além dos softwares educativos, o potencial de difusão das informações pela Internet e a transposição dos museus de ciência para o meio digital ou a realidade virtual tem sido apresentado em diversos artigos (Bearman e Trant, 1999; Díaz e del Egido, 1999; Hawkey, 2001; Kenkerdine, 1998; Sabbatini, 2004; Urban, Marty e Twidale, 2007). Entretanto, essa potencialidade não tem sido realizada e maior parte dos sítios encontrados na Internet sobre exibições museológicas consiste em simples páginas de natureza promocional, contendo as informações dos museus e de suas coleções (Bearman e Trant, 1999; Diaz e del Egido, 1999).

Conforme Díaz e del Egido (1999), os sítios dos museus e centros de ciência poderiam ser classificados em uma das três formas seguintes: i) a primeira categoria, que compreenderia os sítios que contém simples informações sobre a instituição e indica ao público as coleções e mostras que ele pode encontrar ao visitar presencialmente os museus; ii) a segunda categoria envolveria ferramentas utilizadas com finalidade educacional, principalmente por professores e alunos do ensino secundário, onde os sítios das instituições mostram coleções de objetos digitalizados (desenhos, fotos, sons e vídeos, por exemplo) com intuito de divulgar e disseminar o conhecimento científico; e iii) a terceira categoria de informações contempla as coleções e exibições de valor histórico. Por exemplo, o Exploratorium, um museu de ciências que privilegia a manipulação em suas exibições e que foi destacado na secção anterior, é classificado, por esses autores, na segunda categoria.

É nesse sentido que Schweibenz (2004) indica que os museus virtuais na internet estão "em construção" há mais de dez anos e que, uma vez que não haja uma definição amplamente aceita para esse tipo de museu, muitas expressões tem sido utilizadas como sinônimos, tais como: museu on-line, museu eletrônico, hipermuseu, museus digital, cybermuseu e museu em rede. Dessa forma, Schweibenz (2004) e Battro (1999) sugerem que a idéia subjacente à construção de uma expressão digital de museus na Internet é aquela de André Malraux de um "museu sem muros".

Através da proposição de Schweibenz (2004), as iniciativas chamadas de museus virtuais encontrados na Internet poderiam ser classificados da seguinte forma:

a) Museu brochura, que é um sítio na Internet que contém as informações básicas sobre o museu, os tipos de coleção e as exposições temporárias que podem ser encontradas em uma visitação "presencial" ao museu;

b) Museu de conteúdos, que é um sítio na Internet que apresenta as coleções e exibições do museu e convida o visitante virtual as explorar on-line. Os conteúdos são apresentados conforme a classificação dos objetos, de maneira, geralmente, idêntica com as coleções exibidas na realidade. Dessa forma, os conteúdos didáticos não são destacados, pois o objetivo desses sítios é prover um retrato adequado do acervo dos museus.

c) Museu de aprendizagem, que é um sítio na Internet que oferece aos visitantes virtuais diferentes formas de acesso às coleções, por exemplo, de acordo com sua idade, seu conhecimento prévio ou estilo de aprendizagem. Assim, as informações são apresentadas de uma forma mais orientada pelos contextos do que pelos objetos em si e as possíveis características didáticas das coleções e das exibições são realçadas. O objetivo de um museu de aprendizagem é fazer o visitante virtual voltar a visitá-lo e estabelecer um relação pessoal com a exibição e a coleção virtual. 
d) Museu virtual, que é a próxima etapa de um museu de aprendizagem, que provê não apenas informações sobre as coleções dos museus, mas, também, interliga as coleções digitais. Nesse sentido, as exibições digitais não possuem correspondentes na realidade, ou seja, em museus existentes no mundo real.

Lepouras, Katifori, Vassilakis e Charitos (2004) indicam diversas razões que podem justificar os esforços empreendidos no desenvolvimento de museus ou de exibições virtuais: i) falta de espaço físico; ii) simulação de ambientes (que não possuem mais existência atual ou real, que necessitem ser reconstruídos, que são dificilmente alcançados, devido sua distância ou dificuldade de acesso, ou que sua visitação seja difícil ou perigosa); e iii) mobilidade da exibição (que pode ser acessada de maneira remota, desde locais muito distantes da exibição real, por múltiplos visitantes, ao mesmo tempo, de formas diferentes).

Walczak, Cellary e White (2006) sugerem que museus, em todo o mundo, possuem inúmeros artefatos que não são exibidos ao público devido, entre outros motivos, aos espaços limitados, a fragilidade dos objetos ou ao elevado custo para criar e manter as apropriadas exibições. Nesse sentido, sugerem que as tecnologias de realidade virtual e de realidade aumentada oferecem uma forma ideal de apresentação dos artefatos de museus e de outras instituições de herança cultural, produzindo verdadeiros museus virtuais, nos quais os visitantes podem interagir com os conteúdos digitais de forma fácil e natural, como eles fariam com os objetos concretos e reais, caso fosse possível. Porém, Lepouras e Vassilakis (2005) advertem que o desenvolvimento de ambientes virtuais, com simulações em 3D, é um processo difícil, custoso e demorado, especialmente quando visto em comparação com os sistemas de informação tradicionais, com gráficos em 2D. Isso ocorre pois o desenvolvimento de aplicativos em realidade virtual requer a cooperação de um grande grupo de pessoas com uma variedade de habilidade em diferentes áreas. Por exemplo, são necessários programadores de sistema, designers visuais e projetistas de interface, arquitetos para o projeto do espaço virtual e especialistas no domínio da ciência exibida, que são essenciais para orientar a seleção dos objetos a serem digitalizados e descrever as formas pelas quais eles serão exibidos e classificados.

Por isso, Lepouras e colaboradores (2004) sugerem que o termo museu virtual pode ser usado sem uma relação direta com a idéia de realidade virtual, ou seja, pode ser utilizado, também, para descrever exibições interativas e não apensas indicar a aplicação de sistemas gráficos imersivos em 3D, como são, por exemplo, as exibições de cultura grega no projeto de Lepouras e Vassilakis (2005) ou os museus residentes no Second Life (secondlife.com), que utilizam um ambiente virtual multi-usuário para exibir artefatos digitalizados em realidade virtual (Urban, Marty e Twidale, 2007).

Em relação à popularização das ciências, Hawkey (2001) sugere que os sítios na Internet de museus de história natural seriam excelentes veículos para comunicar idéias sobre as ciências da vida e da terra para uma audiência ampla e diversa. Porém, ao analisar diversos sítios de museus em língua inglesa (nos Estados Unidos, na Inglaterra e na Nova Zelândia), em relação as abordagens de comunicação das ciências, de metodologia científica e de educação das ciências, conclui que a maioria dos museus ainda não adota uma comunicação científica e uma abordagem de educação em ciências em um perfil mais próxima aos que se discute no âmbito da Didática das Ciências (Hein, 1995; Semper, 1997). Nesses sítios e em seus museus, a ciência é apresentada como uma "verdade revelada" e as formas de comunicação e de educação utilizam um modelo de transmissão unidirecional. 
Através da investigação realizada por Sabbatini (2004), sobre os conteúdos de museus e centros de ciência virtuais ibero-americanos, verificou-se que, no conjunto, o tradicionalismo e a ausência de experiências inovadoras faz com que os museus de ciência na Espanha e na América Latina estejam perdendo a oportunidade única, de experimentar, de inovar e, talvez, de redefinir seu papel e sua missão frente à sociedade.

Nesse sentido, Hertzum (1998), observa que no desenvolvimento de sítios de museus, os artefatos e seus contextos são reutilizados mais que repensados. Assim, os museus deixam de explorar uma oportunidade de transcender seu atual entendimento do que são museus, para que eles servem e como a informação pode ser comunicada. Portanto, sugere que os projetos de museus e exposições em sítios na Internet sejam elaborados segundo a usabilidade, indo além das características dos sítios atuais.

Assim, Seara, Benitti e Raabe (2004) indicam que a concepção de museus virtuais permite o trabalho escolar em uma perspectiva de projetos de aprendizagem, que é uma estratégia que amplia a participação do aluno e que promove uma maior contextualização das atividade de aprendizagem.

\section{Algumas indicações técnicas.}

No desenvolvimento de sítios de museus, Bowen (2000) sugere que não se tente recriar experiências tradicionais de museus na difusão da informação pela Internet. Nesse artigo, em que resenha diversos museus virtuais, exemplifica o Museo Virtual de Artes $E l$ Pais (www.muva.elpais.com.uy) como uma referência a ser seguida. Esse museu uruguaio foi considerado inusitado, uma vez que ele pode ser exclusivamente visitado de forma virtual, pois não existe nenhuma obra real e concreta associada a ele. Porém, o projeto e o desenvolvimento de um museu virtual instigante e de sucesso é certamente uma tarefa difícil e complexa, que envolve questões culturais, científica, ergonômicas e tecnológicas, entre outras (Lepouras e cols., 2004).

Nesse sentido, Van Praët (2004) registra sua experiência no projeto e realização de mostras museológicas. Ele sugere que o sucesso das exibições repousam, primeiramente, na concepção de uma estrutura onde o desenvolvimento de significado e forma, de acordo com o suporte narrativo e cenográfico, pode combinar diversos modelos de exibições, do modelo sistemático ao modelo interativo. Esse modelo de apresentação é mais relevante para certos assuntos que para outros e, por essa razão, seu uso pode falsear o que a ciência é e representa, atualmente. Por exemplo, a análise dos seis maiores temas (astronomia e astrofísica, física, matemática, química, geociências e ciências da vida) apresentados no Palais de la Découverte (www.palais-decouverte.fr), em Paris, e no Exploratorium, em São Francisco, mostram que o tema física, mais do que qualquer outro, oferece muitas demonstrações e manipulações ao visitante, mostrando a potencialidade da física na museologia interativa. Entretanto, o mesmo não ocorre com a química ou as geociências, para citar duas ciências que estão mais próximas do objeto temático dos autores deste artigo (Samrsla, Guterres, Eichler e Del Pino, 2007).

Lepouras e Vassilakis (2005) descrevem as etapas envolvidas no projeto e implementação de museus e de exibições virtuais, que envolvem: i) a seleção das exibições, que envolve os especialistas em conteúdos e o pessoal responsável com as questões educacionais na escolha do tipo de mensagem a ser exposta em relação ao perfil dos possíveis visitantes; ii) projeto do espaço das exibições, que envolve o arquiteto no projeto computacional dos salões, salas e corredores nos quais serão exibidos os objetos da mostra; iii) seleção dos métodos de apresentação, que pode incluir, por exemplo, fotos, áudio, vídeo 
e modelos em 3D; iv) projeto da interação no ambiente, que envolve as contribuições de um especialista em ergonomia e de educadores; v) digitalização dos objetos exibidos (quando for necessário); vi) disposição dos objetos dentro do espaço da exibição, que envolve programação visual; e vii) programação da interação, que, por fim, envolve a programação de sistemas. Em geral, essas etapas são realizadas de forma seqüencial, mas algumas tarefas podem ser feitas em paralelo, com por exemplo, os itens ii) e iii).

A partir das proposições de Aquino, Costa, Wanderley, Bezerra, Lima e Santiago (2007), na proposta de criação, a exposição virtual deverá assumir o caráter permanente de centro de difusão e popularização da ciência, utilizando tecnologias abertas e ampliando a base de pesquisa para o desenvolvimento de inovações semelhantes. Assim, incluem-se em suas finalidade, o desenvolvimento de metodologias de organização (ontologias) e disponibilização de artefatos científicos, tecnológicos, históricos, culturais e pedagógicos, integrando textos, material iconográfico, vídeo e áudio.

Essa iniciativa propõe-se a manter um canal permanente de divulgação científica e tecnológica destinado a alunos e professores do ensino formal, não-formal, informal e ao público em geral. Pretende oferecer atividades lúdicas e educativas de apoio a professores e alunos da rede pública de ensino de todo o país, voltadas a difusão e popularização do conhecimento científico e tecnológico. Além disso, em atividades tais como fóruns e chats via rede, os visitantes poderão acessar e contribuir com a atualização e ampliação permanente do acervo do museu.

Rayward e Twidale (1999) indicam algumas possibilidades técnicas para ampliar as funções docentes em museu virtual, utilizando: i) apresentações de imagens ou de fotografias, vídeos, bem como de outras representações, para os itens e os artefatos em um coleção; ii) arquivos de filmes ou video clips de artistas, arqueólogos, zoólogos, antropólogos, etc., falando sobre seu trabalho em relação aos itens exibidos de uma coleção; e iii) jogos e enigmas projetados para realçar a interação das crianças com o que é representado nas coleções.

Por fim, Núñez e Ochoa (2006) e Chi, Hsu e Yang (2006) chamam a atenção de a implementação de museus virtuais prever a reusabilidade dos objetos de aprendizagem que são desenvolvidos. Chi, Hsu e Yang (2006) indicam a importância de distribuir de forma aberta a descrição formal dos conceitos, dos atributos e de suas relações da área de conhecimento que é representada nos museus digitais. Nesse sentido, esse autores sugerem a utilização de tecnologias baseadas em XML (eXtensible Markup Language, isto é, linguagem extensível de formatação).

\section{Um exemplo em relação à mineralogia.}

Desde 2004 vimos trabalhando em um projeto de pesquisa na área de didática das ciências que relaciona a mineralogia à química. Uma proposta curricular inovadora para o ensino médio foi desenvolvida durante esse projeto e está descrita em Samsrla, Guterres, Eichler e Del Pino (2007). Nesse sentido, aqui indicamos algumas características de uma exposição virtual de mineralogia, conforme projeto que submetemos recentemente ao financiamento do CNPq visando a sua implementação.

A exposição virtual que estamos projetando é baseado, principalmente, nas proposições museológicas suíças do Muséum d'histoire natuelle de Genebra (www.villege.ch/musinfo/mhng/), devido a variedade de suas exposições, e do Natur-Museum (www.naturmuseum.ch) da cidade de Lucerna, devido a interatividade apresentada. A exposição de mineralogia do museu de Genebra é dividida em assuntos que são 
independentes uns dos outros, como por exemplo: sistemas cristalinos (onde se aborda a arquitetura atômica interna da matéria cristalizada), sistemática (apresentação dos minerais segundo a classificação de cátions e ânions, tais como carbonatos, óxidos, silicatos, etc.), os minerais no seu ambiente (em que se faz uma relação com os processos geológicos de formação dos minerais), os minerais e o homem (onde se mostram os minerais relacionados à atividade humana), as pedras preciosas (onde são apresentadas as gemas brutas e lapidadas por classes mineralógicas) e os minerais fluorescentes e fosforescentes. Por sua vez, o museu de Lucerna possui uma apresentação inicial mais interativa que a mostra de Genebra. Nessa parte inicial é apresentada uma vitrine de minerais, com um console com botões que indicam os diferentes elementos químicos, clicando sobre esses botões pode-se reconhecer os elementos químicos (principalmente metais) que formam os minerais. Outra parte da mostra que é diferenciada e que chama à atenção, contém uma série de minerais que são apresentados a partir dos métodos de reconhecimento dos minerais, tais como: traço, brilho e dureza, por exemplo.

A implementação de um museu virtual de mineralogia necessita de uma etapa de modelagem, em que será necessário selecionar os minerais que serão colocados em exposição. Nesse sentido, a seleção dos minerais pode-se dar pela sua relação com natureza e propriedades químicas, ao se escolher os cátions e ânions presentes nos minerais que serão colocados em exposição. As informações das propriedades (físicas, químicas, cristalográficas, entre outras) dos minerais, bem como suas imagens podem ser coletadas nas ferramentas de catálogo que são encontradas na Internet (por exemplo, www.webmineral.com). Pensamos em trabalhar com uma amostra de cerca de 300 minerais na exposição do museu virtual. Nesse sentido, esses minerais devem, ainda, ser postos em relação com os eixos temáticos que nortearão sua apresentação, conforme as mostras museológicas de Genebra e de Lucerna.

A navegação na exposição será realizada em primeira pessoa, utilizando o movimento de ponto de vista (câmara) para focar as diferentes salas e alas da exposição. O usuário terá, também, a sua disposição, um croqui da ambientação da exposição, verificando as alas da exposição em que centrar sua atenção para obter informações sobre os minerais. Ao parar em uma das alas, o usuário terá acesso as imagens dos minerais em relação aos eixos temáticos através dos quais estes são apresentados. Clicando sobre essas imagens, o visitante poderá obter diversas informações sobre os minerais. A implementação será feita com elementos gráficos que permitam uma boa qualidade de imagem e contará, também, com algumas animações. Nesse sentido, pretende-se produzir uma imagem com perspectiva isométrica ${ }^{2}$ com movimentação de câmara (ponto de vista) em apenas uma dimensão (podendo ser no eixo x, conforme o Museo Virtual de Artes El Pais www.muva.elpais.com.uy - ou no eixo y, conforme o Museo Virtuale di Architettura www.muva.it) que permitirá ampliar substancialmente a qualidade de ambientação da exposição virtual de mineralogia. Essa imagem pode ser produzida com o 3D Studio, Blender ou Rhinoceros 3D.

Como fator motivacional para a navegação pela exposição virtual, pretende-se desenvolver uma sala de descoberta, onde será oferecido ao usuário uma coleção de

\footnotetext{
${ }^{2}$ Entre todas as perspectivas paralelas (não-cônicas), as isométricas são as mais comuns de serem utilizadas no dia-a-dia de escritórios de projeto (de arquitetura, engenharia, design, etc), devido à sua versatilidade e facilidade de montagem A perspectiva isométrica foi bastante utilizada em jogos de computador que, não podendo simular os efeitos de uma perspectiva cônica devido às limitações tecnológicas, pretendia simular uma realidade tridimensional.
} 
amostras de minerais desconhecidos, que deverão ser classificados e identificados, conforme experiência realizada por Guterres, Eichler e Del Pino (2007). Além disso, também, serão desenvolvidas ferramentas de interação social, síncrona e assíncrona, podendo ser usados chats e fóruns. Na implementação da exposição virtual serão utilizadas tecnologias Macromedia, como o Flash e o ActionScript, e sistemas de banco de dados PHP, ou equivalente.

Por fim, pretende-se criar uma sala de mostras temporárias no ambiente da exposição virtual de mineralogia. Essas mostras temporárias, poderão ser substituídas semestral ou anualmente, ficando, posteriormente, disponíveis em um acervo virtual. A primeira dessas mostras terá como título: Algumas paisagens sob um olhar químico. Essa mostra consistirá em seis animações de seqüências de imagens de paisagens coletadas, principalmente, no Flickr.com. Os temas que orientam cada uma dessas seis seqüências foram adaptados, em geral, da iconografia apresentada nos livros de Bourseiller e Durieux (2001), Kraft (1991) e Pradal e Decobecq (2004) e compreende os seguintes assuntos: 1) paisagens vulcânicas: diversidade e beleza; 2) lagos ácidos e básicos: alguns lagos vulcânicos ao redor do mundo e o Lago Natron (Tanzânia); 3) paisagens salinas: as piscinas de decantação e as formas dos carbonatos em Pumakkale (Turquia); 4) as montanhas coloridas: as paletas do artistas em Zabrieskie Point (Estados Unidos) e em Landmannalaugar (Islândia); 5) as atividades de mineração e o impacto ambiental da extração do cobre e do níquel; e 6) a produção de enxofre: as fumarolas na Ilha de Volcano (Itália) e em Kawah Ijen (Indonésia).

Referências bibliográficas:

ADAMS, J. The historical context of science and education at the American Museum of Natural History. Cultural Studies of Science Education, 2, 393-422, 2007.

ALBERTI, S.J.M.M. Objects and the Museum. Isis, 96, 559-571, 2005.

AQUINO, M.A.; COSTA, A.R.F.; WANDERLEY, A.C.C.; BEZERRA, L.T.; LIMA, I.F.; E SANTIAGO, S.M. A ciência em ação: o museu virtual de imagens da cultura africana e afrodescendente. Inclusão Social, 2 (1), 18-29, 2007.

BAMBERGER, Y. \& TAL, T. Learning in a personal context: levels of choice in a free choice learning environment in science and natural history museums. Science Education, 91 (1), 75-95, 2007.

BATTRO, A. Del museo imaginario de Malraux al museo virtual. Em: Xth World Congress Friends of Museums, Sidney, Austrália, 13 a 18 de setembro. [Documento digital em: http://www.byd.com.ar/mv99sep.htm, acessado em setembro de 2007], 1999.

BEARMAN, D. \& TRANT, J. Interactivity comes of age: museums and the World Wide Web. Museum International, 51 (4), 20-24, 1999.

BEVAN, B. Transformation and the third space of school-museum collaborations. Cultural Studies of Science Education, 2, 429-437, 2007.

BOWEN, J. The virtual museum. Museum International, 52 (1), 4-7, 2000.

BOURSEILlER, P. E DURIEUX, J. Des volcans et des hommes. Paris: Editions de la Martinière, 2001.

CHI,Y.-L.; HSU, T.-Y.; YANG, W.-P. Ontological techniques for reuse and sharing knowledge in digital museums. The Electronic Library, 24 (2), 147-159, 2006. 
COX-PETERSEN, A.M.; MARSH, D.D.; KISIEL, J.; MELBER, L.M. Investigation of guided school tours, student learning, and science reform recommendations at museum of natural history. Journal of Research in Science Teaching, 40 (2), 200-218, 2003.

DÍAZ, L.A.B. \& DEL EGIDO, A. Science museums on the internet. Museum International, 51 (4), 35-41, 1999.

FORGAN, S. Building the Museum: knowledge, conflict and the power of place. Isis, 96, 572-585, 2005.

GUTERRES, J.O.; EICHLER, M.L.; DEL PINO, J.C. Análise de um caso exemplar da microgênese da identificação e da classificação de minerais. Em: VI Encontro Nacional de Pesquisa em Educação em Ciências, Florianópolis, 26 de novembro a $1^{\circ}$ dezembro de 2007. (a aparecer).

HAWKEY, R. The science of nature and the nature of science: natural history museums online. Electronic Journal of Science Education, 5 (4) [Documento digital em: http://wolfweb.unr.edu/homepage/crowther/ejse/ejsev5n4.html, acessado em setembro de 2007], 2001.

HEIN, G.E. The constructivist museum. Journal for Education in Museums, 16, 21-23, 1995.

HERTZUM, M. A review of museum web sites: in search of user-centred design. Archives and Museum Informatics, 12, 127-138, 1998.

KELLY, L. Evaluation, research and communities of practice: program evaluation in museums. Archival Science, 4, 45-69, 2004.

KENDERDINE, S. Sailing on the silicon sea - the design of a virtual maritime museum. Archives and Museum Informatics, 12, 17-38, 1998.

KRAFT, M. Les feux de la terre - Histoires de volcans. Paris: Gallimard, 1991.

LEPOURAS, G. \& VASSILAKIS, C. Virtual museums for all: employing game technology for edutainment. Virtual Reality, 8, 96-106, 2005.

LEPOURAS, G.; KATIFORI, A.; VASSILAKIS, C.; CHARITOS, D. Real exhibitions in a virtual museum. Virtual Reality, 7, 120-128, 2004.

MARTÍNEZ, E. La pirámide de la popularización de la ciencia y la tecnología. Em: E. Martínez e J. Flores (Orgs.), La Popularización de la Ciencia y la Tecnología: reflexiones básicas (pp. 9-16). México: UNESCO, RedPop, Fondo de Cultura Económica, 1997.

MELBER, L.M. \& ABRAHAM, L.M. Science education in U.S. Natural History Museums: a historical perspective. Science \& Education, 11, 45-54, 2002.

MOREIRA, I.C. A inclusão social e a popularização da ciência e tecnologia no Brasil. Inclusão Social, 1 (2), 11-16, 2006.

NÚÑEZ, Y.O. \& OCHOA, P.C. Propuesta para el diseño de objetos de aprendizaje design of learning objects propost. Revista Facultad de Ingeniería (Tarapacá), 14 (1), 3648, 2006.

PRADAL, E. \& DECOBECQ, D. Au coeur des volcans. Paris: Fleurus, 2004.

RAYWARD, W.B. \& TWIDALE, M.B. From docent to cyberdocent: education and guidance in the virtual museum. Archives and Museum Informatics, 13, 23-53, 1999.

RENNIE, L.J. \& WILLIAMS, G.F. Communication about science in a traditional museum: visitors' and staff's perceptions. Cultural Studies of Science Education, 1, 791-820, 2006. 
SABBATINI, M. Museus y centros de ciencia virtuales. Complementación y potenciación del aprendizaje de ciencias a través de experimentos virtuales. Tese de doutorado. Salamanca: Instituto Universitario de Ciencias de la Educación, Universidade de Salamanca, 2004.

SAMRSLA, V.E.E.; GUTERRES, J.O; EICHLER, M.L.; DEL PINO, J.C. Da mineralogia à Química: uma proposta curricular para o primeiro ano do Ensino Médio. Química Nova na Escola, 25, 20-26, 2007.

SCHWEIBENZ, W. The development of virtual museums. ICOM News, 57 (3), 3, 2004.

SEÁRA, E.F.R.; BENITTI, F.B.V.; RAABE, A. A construção de um museu virtual 3D para o ensino fundamental. INFOCOMP Journal of Computer Science, 4 (1), 78-83, 2004.

SEMPER, R.J. Museos de ciencia: ámbitos para el aprendizaje. Em: E. Martínez e J. Flores (Orgs.), La Popularización de la Ciencia y la Tecnología: reflexiones básicas (pp. 139-151). México: UNESCO, RedPop, Fondo de Cultura Económica, 1997.

TAL, T. \& MORAG, O. School visits to natural history museums: teaching or enriching? Journal of Research in Science Teaching, 44 (5), 747-769, 2007.

URBAN, R.; MARTY, P.; TWIDALE, M. A Second Life for your museum: 3D multi-user virtual environments and museums. Em: Museums and the Web 2007: the international conference for culture and heritage on-line, San Francisco/CA, EUA, 11 a 14 de abril. Documento digital em: http://www.archimuse.com/mw2007/papers/, acessado em setembro de 2007.

VAN PRAËT, M. Heritage and scientific culture: the intangible in science museums in France. Museum International, 56 (1-2), 113-121, 2004.

WALCZAK, K.; CELLARY, W.; WHITE, M. Virtual museum exhibitions. Computer, 39 (3), 93-95, 2006. 